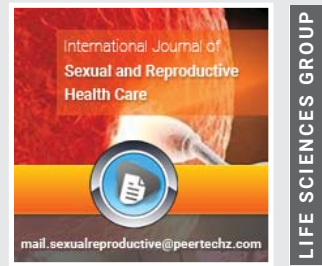

\title{
An exploration of the factors affecting the utilization of family planning services among youth (18-24 years) at community level in rural Budaka district, Uganda
}

\section{George K Kiggundu' ${ }^{1}$, Mathew Nyashanu ${ }^{2 *}$ and Mandu S Ekpenyong ${ }^{3}$}

${ }^{1}$ Project Manager Millennium Promise Alliance, Inc Kampala Uganda

${ }^{2}$ Senior Lecturer Nottingham Trent University Institute of Health \& Allied Professions, UK ${ }^{3}$ Research Associate, Manchester Metropolitan University Faculty of Health, Psychology \& Social Care, UK

Received: 24 January, 2020

Accepted: 09 March, 2020

Published: 10 March, 2020

*Corresponding author: Dr. Mathew Nyashanu, (B.Ed. MA MPH PhD), Senior Lecturer Nottingham Trent University Institute of Health \& Allied Professions, UK, Tel: +447973229733;

E-mail: mathew.nyashanu@ntu.ac.uk

ORCID: https://orcid.org/0000-0002-9231-0393

Keywords: Young people; Family planning; contraceptives; Black sub-sahara africans

https://www.peertechz.com

\section{Check for updates}

\begin{abstract}
Background: There is an increased number of young people engaging in early sexual relationships worldwide. Furthermore, statistics for early pregnancy among young people has also increased especially in low and middle-income countries. This has health implications for both the parents and the baby. High uptake in family planning contraception among the young people can reduce early pregnancy and subsequent negative health outcomes on the young parents and the baby. This study was set to explore the factors influencing the uptake of family planning contraceptive services among young people (18-24 years) at community level in rural Budaka district, Uganda.
\end{abstract}

Method: The study utilised an explorative qualitative approach. Eight focus group discussion were conducted followed by sixteen one to one follow up semistructured interviews with young people. Each focus group comprised of 10 participants $(\mathrm{N}=80)$. Sixteen one to one follow up interviews were meant to further explore issues raised in the focus groups $(\mathrm{N}=16)$. A thematic approach underpinned by the four phases of The Silences Framework (TSF) was used to analyse the data.

Results: The study found out that religion, partner resistance; perceived loss of libido, perceived barren, long waiting time and distance from the health facility, lack of privacy/confidentiality, excessive menstrual bleeding, cancer and fear of having disabled babies, limited the utilisation of family planning contraceptive services while contraception as HIV prevention and child spacing encouraged young people to use family planning contraceptive services.

Conclusion: There is need for a culturally orientated community-based contraceptive health promotion approach to increase the uptake of family planning contraception services among young people.

\section{Introduction}

Globally there are over 1.8 billion young people and almost 90 percent of them, live in low and middle-income countries [1]. Most of these young people start to explore sexual activities between the ages of 15 to 24 years. Furthermore, nearly all young people become sexually active by their $20^{\text {th }}$ birthday worldwide and 75 percent of young women in sub-Saharan Africa, report engaging in sex by the time they are 20 years old [2]. Studies have shown that those who engage in early sexual 
relations are at risk of having unwanted pregnancy and sexual transmitted infections [3]. Engaging in sexual relations at an early age, without or with very little contraception knowledge and understanding can predispose these young people to an array of sexual transmitted infection including HIV and earlyunplanned pregnancy [4].

The prevalence of unintended pregnancies, unsafe abortion, maternal mortality, injuries and sexually transmitted infections including HIV among youth in low and middle-income countries are extremely high [5]. Moreover, it is reported that one out of 10 abortions globally and one out six births occur in low income countries annually among women of 15-19 years respectively [6]. In addition, every day half a million of youth get infected with a sexually transmitted infection worldwide thereby demonstrating the significance of this public health [6]. Nearly 12 million youth have are living with HIV and more than, 7000 youth are infected with HIV each day worldwide with the majority living in low- and middle-income countries [7]. On the other hand, around 16 million adolescent girls 15 to 19 deliver annually, contributing to more than 10 percent of the total deliveries globally World [7]. The reproductive options of youth have a vast effect on their health, education, employment opportunities and general transformation into adulthood [8]. Primarily, early childbirth is associated with high prevalence of maternal and childhood illness and death, reduced chances for schooling, poverty in the family due to lower income, large family sizes thus leading to population explosion [9].

Studies indicate that utilising family planning services is good for women's health as well as a novel idea as an HIV prevention strategy [10]. Moreover, providing contraceptives to women as a strategy to prevent babies born with HIV is viewed as more cost efficient than providing Nevirapine for mothers infected with HIV attending antenatal care [10]. Available literature shows that generally, young people who are sexually active and are not married may not want to get pregnant, while young people, who are married, might still not want to have children until a certain point in their life [11]. It is imperative that these young people are given a choice to realise their goals, through the provision of a robust and affordable contraceptive service. In spite of these facts, the rate of contraceptive utilisation prevalence in Sub-Sahara Africa is pegged at $\mathbf{2 1}$ percent for women in general with even lower contraceptive prevalence rate for adolescent girls [12]. There has been a range of service delivery strategies utilized to distribute family planning services to underprivileged groups like the youth in low and middle-income countries [13]. The common strategies used to deliver family planning include health posts, health units, health centres, hospitals and community-based distribution that encompasses commercial retail sale, door-to-door service delivery and distribution at the workplaces [12]. The facility-based model provides family planning services through public health centres and hospital whereas the community health worker who live within the communities can provide the same service which is personal and culturally orientated [14]. Furthermore, utilization of modern contraceptive services is advantageous, since it provides medically complex methods such as Intra uterine contraceptive devices, hormonal implants and sterilization
[14]. Such professionally staffed, and quality approved services are important and safe for use by communities [15]. Apart from constrained resources and facilities for family planning contraception services in low and middle-income countries, there is also a problem with the uptake of these services owing to a number of societal based factors [16]. Currently there is very limited research exploring the factors influencing access to contraceptive services in sub-Sahara Africa. Therefore, this research study is set to explore the factors influencing the utilisation of family planning services among young people (18-24 years) at community level in rural Budaka district, Uganda.

\section{Conceptual framework}

The Health belief Model (HBM) and some aspects of The Silences framework (TSF) guided this study. The HBM proposes a small number of variables that can describe a significant percentage of difference in any behaviour within a given population [17]. Furthermore, following a behaviour depends on the attitudes people have about that behaviour. The pre-eminent predictor of individual's behaviour is the intent to execute that behaviour [18]. When someone plans to execute a behaviour, health belief model predicts they will do so, given that they have the required abilities and skills and as long as the environmental factors do not interfere with the performance of the behaviour [18]. The purpose of an individual to execute a behaviour is based on their attitude towards the behaviour, perceived belief related to the behaviour as well as self-efficacy associated with the behaviour [17]. Within the HBM model, attitudes indicate how favourable or unfavourable an individual thinks his execution of the behaviour will be. Moreover, perception of norms points out the social pressures an individual feel to perform the behaviour [17]. The social pressures associated with the behaviour points out the importance, if people value the behaviour or if peers are literally performing the behaviour [18]. Ultimately, self-efficacy entails an individual's belief, if they can ably execute the behaviour, notwithstanding their real skilfulness [18]. The background factors like socio-economic status, relationship issues, and education can affect attitudes, perceived norms as well as selfefficacy. It is against this background that issues influencing the utilisation of contraceptive services among young people were identified and explored. TSF is suitable for researching marginalised and sometimes sensitive issues in communities [19]. For example, issues of sexual health and contraception are regarded as sensitive and sometimes difficult to talk about among black sub-Sahara African (BSSA) communities. This study also adopted the stage 3 of the silence framework, which clarifies the refinement of themes during data analysis.

\section{Methodology}

An explorative qualitative approach was adopted for this study, using focus group discussion and semi-structured interviews. Data was collected from young people residing and utilising contraceptive services in Budaka district. Purposive sampling method was utilised to select the study participants based on their location, sex and utilisation of contraceptive services [20]. 
Eight focus group discussion were conducted followed by sixteen one to one follow up semi-structured interviews with young people. Each focus group comprised of 10 participants $(\mathrm{N}=80)$. Sixteen one to one follow up interviews were meant to further explore issues raised in the focus groups $(\mathrm{N}=16)$. In order for the researcher to get the true lived experiences of the participants, focus group discussion were conducted with female participants and male participants who had used contraceptive services in Budaka district. The ethics committee of Nottingham Trent University approved the research Study. The ministry of health in Uganda also granted approval for the research study to be conducted. All the study participants were identified and contacted through the health workers at contraceptive services in Budaka District. Focus group discussion with the young people lasted for 1 hour and the one to one follow up interviews lasted for one hour. All interviews and focus group discussion were audio taped and transcribed verbatim, and the transcribed data were thematically analysed in line with the four phases of TSF tabulated below [19].

Stage 1. After transcription, the researcher analysed output from the interview and focus group discussion, and recurrent themes were identified as initial finding.

Stage 2. The research participants then reviewed stage 1 results. Feedback from the participants was used to critique, confirm or refute the findings in stage 1 . A robust discussion of the silences (findings) was made.

Stage 3 Phase 3. Information from phase 3 was further analysed through social networks of the participants. The social network was drawn from people who had not taken part in the initial focus groups and one to one follow up interviews. The aim was to authenticate the findings from phase 2 with a critical indirectly associative analysis from a group that mirrors lived experiences of the research participants.

Stage 4. The researcher reflected on the findings of stage 1 and 2, revisiting, reviewing and developing emerging research findings, which were then taken as the final research results of this study.

Analysis of the data uncovered the attitudinal and noattitudinal factors which affect the utilisation of family planning services among the youth.

\section{Results}

Following analysis of the focus groups and one to one follow up interviews the following themes supported by captions from research participants were generated:

\section{Religion}

Most of the research participants felt that using contraceptives for family planning was not acceptable owing to the ethos and values of their faith and religion.

"Being a Muslim, it forbids me from using Contraceptives. God instructs us to multiply and replenish the earth". (18-year-old Female participant).
"I am a Pentecostal; my religion does not allow me to use family planning methods, to have children that we can take care of" (16year Male participant)

\section{Partner resistance (Cultural significance of children)}

Many female research participants felt that use of contraception was strongly opposed by their partners citing cultural beliefs that the primary objective in marriage is to have children.

"My partner is strongly opposed to any form of contraception because he beliefs that the reason why we got married was to have as many children as possible" (21-year-old female participant).

"A man 's status is measured by the number of children he has I am strongly opposed to all this contraception business undermining the values and ethos of traditions" (24-year-old male participant)

\section{Perceived loss of libido}

Most research participants perceived that use of contraceptive for family planning can lead to loss of libido thus causing marital breakdowns.

"I do not trust these contraceptives for family planning they can really destroy your sexual desire. My aunt has always been advising me against using them and warned me that my marriage will breakdown" (A 22-year-old female participant).

"Since growing up we were being told that using family planning contraception can affect your womanhood I mean sexual appetite and that can cause problems in your marriage or relationship" (A 23-year-old female participant).

\section{Perceived barren}

The research participants felt that the using of family planning contraception while young can lead to loss of fertility resulting in divorce.

"Youth should not use family planning; it prevents them from having children later in life. For instance, if you have a large piece of land, who will cultivate this land if you do not have children. In addition, the use of contraceptives leads to deformed babies and children with low intelligence quotient (A 24-year-old Male participant).

"My feeling is that Youth should not use family planning methods because it affects the uterus and they have to remove it. If you use contraceptives before having children, it may be difficult later to have children when the uterus is removed. Family planning contraception is good for older women who have produced the desired number of children and they wish to stop." (22-year old Female participant)

"In my culture when you pay dowry the woman is expected to deliver children as a symbol of appreciation for the dowry you paid. Therefore, if you are married, you are not expected to use any family planning method (A 22-year-old male participant).

\section{Long waiting time and distance from the health facility}

Further discussion on availability of services disclosed that 
even when methods are available, youth reported on missing the services sometime because the providers are too busy to attend to them or they spent a long time waiting to be attended to.

"Although contraceptives are available, if you have other commitments and you're in a rush, you would rather leave it until you have time, Sometimes there is a long que waiting for one nurse to perform contraceptive procedures on more than forty people". (A 22-year-old female participant)

"Sometimes you have to travel more than two hours to get to the clinic and then wait for further two hours while waiting for one nurse who is skilled to fit in the implants honestly it is taxing. I sometimes feel I would rather leave it" (A 23-year-old female participant)

\section{Lack of privacy/Confidentiality}

"There is no privacy at that clinic you hear the nurses shouting to people attending the clinic to line up for implants or tablets. Everyone will know why you are at the clinic. Honestly there is need for the nurses to put some form of privacy for service users" (19-year-old female participant)

"There is lack of privacy at that clinic, everyone can easily know why you are at the clinic sometimes the staff just shout out private information in front of others service users" (A 24-year-old female participant)

\section{Contraception as HIV prevention and child spacing}

Female young people using family planning methods reported that they had overcome discontentment from the community to start using family planning methods. The young people preferred contraception for different reasons, which include, the benefits associated with child spacing, delaying next pregnancy, protection from sexually transmitted diseases including HIV/AIDs and that these contraceptives are free of charge.

"As a married young person, I and my partner always visit the health facility for free for condoms when we run out of supplies and these are given freely by the health workers. They have helped us to space our children well". (A 23-year-old Female participants)

"Family planning method helps me to have children that me and my partner can provide for in terms of education and food, It is also important because it protects me from sexual transmitted infections including HIV when I decide to get a new partner " (A 22 year old male participant)

\section{Perceived menstrual interference, Fear of cancer and having a disabled child}

The research participants expressed a strong fear of side effects caused by family planning contraception. Some believed that family.

"Youth should not use family planning methods because they interfere with their menstruation cycles and cause excusive bleeding. My mum experienced it until she just stopped using contraception". (A 22-year-old Female participant)
"I have known people who have been using family planning contraception for a long time. They only stopped taking contraceptives when they were experiencing bleeding. Honestly it is fearful. (23-year-old Male participant)

The research participants expressed perceived fear of cancer caused by using family planning contraception.

"I may be wrong, but it is public knowledge that family planning contraception is a source of all these untreatable chronic conditions including cancer that killed my mother" (A 24-year-old male research participant).

"Honestly all these cancers that are troubling us today are caused by some of these family planning contraceptives, we really need to find a solution to this. All these diseases never affected us in the olden days until family planning contraceptives started to be used" (A 22-year-old male participant).

\section{Fear of having a disabled child}

The research participants believed that children born with disability were being exacerbated by using family planning contraception.

"Family planning contraception is the source of all these disabled children we have in our communities. Just look at how many children are being born with disability today compared to the olden days" (A 23-year-old male participant)

"Honestly increased use of contraception can be linked to use of family planning contraception, my grand father told me that these problems came with the use of family planning contraceptives" (A 24-year-old male participant).

\section{Discussion}

Following the presentation of the results supported by captions from lived experiences and attitudes of research participants towards the use of family planning contraceptives a detailed discussion was undertaken to unpack the themes identified during data analysis and presentation.

Religion is a very important and integral part of life within many BSSA communities [12]. It is against this background that the research participants felt that using family planning contraception was a religious traverse of justice that is totally opposed to the ethos and values of the religion that bind and protect them [21]. Such beliefs in communities are not new. In many occasions, religion through its sacredness has been used to disapprove scientific proven ideas and practices [22]. In doing so patriarchy has found power in justifying and perpetuating the ethos and values that protects the interest and power of men in many African societies and the world at large. It is important that health professionals and women are equipped with knowledge and understanding to engage and challenge these retrogressive perceptions advanced by men to perpetuate their patriarchal superiority complex [23]. By so doing, there is need to demarcate the benefits of religion and distorted claim to societal development through a broad community-based education approach that fosters honesty 
and integrity to the most vulnerable members of the human society namely children young people and women in general [24]. While religion boasts of so many benefits in society it is important to guard against its use as an opium to society as propounded by Max [25]. Such assertiveness can guard against victimisation and oppression of women to bend to the whims and desire of men during the transaction of family planning contraception processes.

Both female and male participants reported partner resistance to the use of contraception. This notion was based on the premise that the essence of marriage as valued and recognised among BSSA communities is to bear as many children as possible [26]. It is important to realise that one of the main problems experienced by families in many lowand middle-income countries is child poverty. This is caused by resistance to change and realising that the dynamics of economics has changed where wellbeing of children is shaped by affordability in providing support [27]. It is imperative that staff in family planning clinics are equipped with the right skills to inform communities on the importance of having children they are capable of supporting in terms of education and general wellbeing.

One of the reasons put forward by the research participants as inhibiting the use of family planning contraceptives was fear of losing libido. Though a marginalised issue and sometimes hard to discuss among BSSA communities, libido is central to marriage [28]. The idea of valuing libido is not new among BBSA communities. This is a long running historically entrenched belief that need to be challenged in the modern world in order to advance the status of women 's health. In doing, so there is need for the ministry of health to roll out community-based education to enlighten communities and individuals whose focus on the meaning of marriage is associated with strong libido. However, it is important not to discount the importance accorded to it but to allow communities to also consider an array of issues that constitutes marriage. Partners involved in a union should not be coerced to value an individual factor in defining the essence of family planning contraception. There is need to provide a gender sensitive health promotion approach in dealing with such often marginalised issues but equally important to the core of marriage.

Furthermore, perceived fear of being barren or losing the ability to have children was cited by research participants as a constraining factor in utilising family planning contraception. Traditionally, among BSSA communities marriage is valued by the number of children an individual has [25]. This traditional value comes with many challenges that are not explored and considered by families [29]. There is need for professionals working in family planning to initiate these conversations with families and dispel the myths around the impact of taking family planning contraception. It is important that young people are engaged and allowed to articulate their views, fears and resolutions around the issue as a starting point. Furthermore, involvement of other young people with clear knowledge on the impact of family planning contraception as peer educators can be a viable strategy in eliminating contraception myths
[30]. Such strategies are not new to health promotion, as they have been found to be effective in HIV/AIDS programmes.

Another issue raised by the research participants was privacy and confidentiality accorded to service users by the staff at family planning facilities. It is important that the integrity and respect of service users at clinics or health facilities dealing with sensitive issues like sexual health and contraception is respected and protected [3]. To achieve this milestone there is need for the ministry of health and other partners involved in developing and strengthening the health systems in low and middle-income countries to prioritise staff development through continuous training on important issues like privacy and confidentiality. More importantly, the health facilities need to engage young people and ensure them that their privacy and confidentiality will be maintained at all times while transacting family planning business. Such an assurance should be supported through change in practice and putting the values of service users at the forefront.

The research participants also located excessive menstrual bleeding, fear of cancer and having a disabled child as further inhibiting factors in the utilisation of family planning contraception services. Again, as alluded to earlier on, in this article community driven myths can be more powerful than a positive health message owing to the source and rationale for the creation of the myths [32]. Myths are normally created and disseminated by powerful community gatekeepers to perpetuate sometimes-negative practices. It is therefore important that professionals working in family planning are equipped with skills to engage community gatekeepers, dispel the myths from the core source, and use them as partners in spreading positive family planning contraception messages. In doing so, the power and influence of community gatekeepers is turned to join forces with health professionals in creating myth free community [36].

There was no total rejection or dismissal of contraception by the research participants as they reported that meanwhile they may want to take up family planning contraception, there inhibiting factors that included long waiting time and distance to the to the health facility. This problem is not new in many health systems of low and middle-income countries including developed countries save for the distance travelled to health facilities [25]. There is need for governments in low and middle-income countries to consider strengthening their health systems through community empowerment and training of local people as community Health workers (CHWs). CHWs can help in performing or dispensing non-complex family planning procedures or distributing family planning tablets and condoms in community centres like shops, faith centres and community halls to mitigate distance travelled to health facilities by young people [33]. Such services can increase the uptake of family planning contraception services among young people and the community at large.

Furthermore, the research participants showed appreciation of some family planning contraception methods like male and female condoms as vital for both HIV prevention and child spacing. It is important to note that although 
there are many inhibiting factors in the utilisation of family planning contraceptives there is also acknowledgement of positive outcomes on the use of contraception by the research participants. The realisation of the importance of family planning contraception as a double benefit by the young people should be positively celebrated and perpetuated by the health professionals through continuous dialogue with young people and the community at large [34]. Such reinforcement of positive behaviour is a key health promotion strategy to counter inhibiting factors in the uptake of family planning contraception services among young people and the community at large.

\section{Implication for practice}

There is a growing need for policy makers in low- and middle-income countries to consider robust family planning contraceptive policies which addresses specific needs for young people. More importantly inclusive health promotion programmes involving communities and their gatekeepers are key in tackling many inhibiting factors to the uptake of family planning contraception. There is need to invest in continuous staff development trainings to make sure that the workforce in family planning contraception is kept abreast with new changes and challenges emerging in the field [35]. A more substantive comprehensive research assessing wider factors influencing the uptake of family planning contraception need to be undertaken with a view to develop an effective intervention to increase the uptake of family planning contraception among young people in Uganda.

\section{Limitations of the study}

This research was only carried out in Budaka district utilising a qualitative research paradigm, while Uganda has so many districts. It is therefore difficult to draw conclusions from this study about the general factors influencing the uptake of family planning contraception among young people in Uganda. A more geographical and population sample representative research is needed.

\section{Concluding comments}

The findings from this study identified both positive and negative factors influencing utilization of family planning contraception. However, the majority of young people used contraceptives to prevent unplanned pregnancies; sexually transmitted diseases including HIV/AIDs in order to remain in school and finish their education. There were more inhibitors than enhancers in factors that influenced the utilisation of family planning contraceptives.

\section{Acknowledgements}

Our sincere gratitude goes to the community of Budaka district in Uganda who participated in this research study

\section{Funding}

This research was funded by the Commonwealth Scholarship

\section{References}

1. Hindin MJ, Fatusi AO (2009) Adolescent sexual and reproductive health in developing countries: an overview of trends and interventions. Int Perspect Sex Reprod Health 35: 58-62. Link: https://bit.ly/32ZKWZt

2. Calvert C, Baisley K, Doyle AM, Maganja K, Changalucha J, et al. (2013) Risk factors for unplanned pregnancy among young women in Tanzania. J Fam Plann Reprod Health Care 39: e2. Link: https://bit.ly/2TTPZX0

3. Dixon-Mueller R (2009) Starting young: Sexual initiation and HIV prevention in early adolescence. AIDS Behav 13: 100-109. Link: https://bit.ly/3cHGD9A

4. Team YA (2004) Assessment of youth reproductive health programs in Ethiopia. Link: https://bit.ly/3cKrfcj

5. Adongo PB, Phillips JF, Kajihara B, Fayorsey C, Debpuur C, et al. (1997) Cultural factors constraining the introduction of family planning among the Kassena-Nankana of Northern Ghana. Soc Sci Med 45: 1789-1804. Link: https://bit.ly/38BAPv5

6. Mensch BS, Grant MJ, Blanc AK (2006) The changing context of sexua initiation in sub-Saharan Africa. Popul Dev Rev 32: 699-727. Link: https://bit.ly/3aDOK55

7. World Health Organization (2008) Why Is Giving Special Attention to Adolescents Important for Achieving Millennium Development Goal 5?. Link: https://bit.ly/2vPHynJ

8. National Research Council, Lloyd CB (2005) Executive Summary: Growing Up Global: the Changing Transitions to Adulthood in Developing Countries. National Academies Press. Link: https://bit.ly/39wd8Wd

9. Ashcraft A, Lang K (2006) The consequences of teenage childbearing (No w12485). National Bureau of Economic Research. Link: https://bit.ly/2v4rnT6

10. Reynolds H, Janowitz B, Homan R, Johnson L (2005) Cost-effectiveness of two interventions to avert HIV-positive irths.

11. Cleland J, Ali MM, Shah I (2006) Trends in protective behaviour among single vs. married young women in sub-Saharan Africa: the big picture. Reprod Health Matters14: 17-22. Link: https://bit.ly/39Bo9pk

12. Nanyonga B (2018) Voices of Female Youths Living with HIV/AIDS on their Experiences regarding access and Utilisation of Contraceptives: A case of Kawempe Division Kampala City, Uganda. Link: https://bit.ly/2KbCehX

13. Ahmed S, Ahmed S, McKaig C, Begum N, Mungia J, et al. (2015) The effect of integrating family planning with a maternal and newborn health program on postpartum contraceptive use and optimal birth spacing in rural Bangladesh. Stud Fam Plann 46: 297-312. Link: https://bit.ly/3cNGkdx

14. Katz KR, WestCG, Doumbia F, KaneF(1998) Increasing access to familyplanning services in rural Mali through community-based distribution. International Family Planning Perspectives 24: 104-110. Link: https://bit.ly/38DfFwq

15. Jones PW (2007) World Bank financing of education: Lending, learning and development. Routledge. Link: https://bit.ly/2TxwUuR

16. Fabic MS, Choi Y, Bongaarts J, Darroch JE, Ross JA, et al. (2015) Meeting demand for family planning within a generation: the post-2015 agenda. Lancet 385: 1928-1931. Link: https://bit.ly/2vGPY0Q

17. Fishbein M, Jaccard JJ (1973) Theoretical and methodological considerations in the prediction of family planning intentions and behavior. Representative Research in Social Psychology 4: 37-51. Link: https://bit.ly/2wFDYwO

18. Yzer M (2012) The integrative model of behavioural prediction as a tool for designing health messages. In $\mathrm{H}$. Cho (Ed.), Heath Communication Message Design: Theory and Practice. Thousand Oaks: Sage. 21-40. Link: https://bit.ly/2PXqGIZ 
19. Serrant-Green $L$ (2011) The sound of 'silence': A framework for researching sensitive issues or marginalised perspective in health, $\mathrm{J}$ Res Nurs 16: 1-14. Link: https://bit.ly/2Q17iEF

20. Denscombe M (2014) The Good Research Guide; For Small-scale socia research Projects $5^{\text {th }}$ edition, New York. Open University Press. Link: https://bit.ly/38AA6dF

21. Bakibinga $P$, Mutombo N, Mukiira C, Kamande E, Ezeh A, et al. (2016) The influence of religion and ethnicity on family planning approval: a case for women in rural Western Kenya. J Religion Health 55: 192-205. Link: https://bit.ly/3co40su

22. Hollos M, Larsen U (2008) Motherhood in sub-Saharan Africa: The social consequences of infertility in an urban population in northern Tanzania. Culture, Health \& Sexuality 10: 159-173. Link: https://bit.ly/2Vfk1GS

23. Sanger N, Hadland A (2008) Challenging patriarchal scripts? A gender analysis of South Africa's community print media. Agenda 22: 4-17. Link: https://bit.ly/3be8q0b

24. Makundi FL (2001) Quality of Care and Accessibility of Family Planning Services in Tanzania: Providers', Clients', and Non-Users' Perspectives. In paper delivered at the annual meeting of the Population Association of America, Washington, DC. Link: https://bit.ly/2XQUI59

25. Hollos M, Larsen U, Obono O, Whitehouse B (2009) The problem of infertility in high fertility populations: meanings, consequences and coping mechanisms in two Nigerian communities. Social science \& medicine 68: 2061-2068. Link: https://bit.ly/3esHifJ

26. Mair LP (2013) African marriage and social change. Routledge. Link: https://bit.ly/2xp5Tli
27. Cass B (2007) The goals of a good national system: Placing priority on the wellbeing of children. Sydney University Press. Link: https://bit.ly/3bpOQhL

28. Elliott S, Umberson D (2008) The performance of desire: Gender and sexual negotiation in long-term marriages. J Marriage Fam 70: 391-406. Link: https://bit.ly/3a8pPGc

29. Nalwadda G, Mirembe F, Tumwesigye NM, Byamugisha J, Faxelid E, et al (2011) Constraints and prospects for contraceptive service provision to young people in Uganda: providers' perspectives. BMC health services research 11 220. Link: https://bit.ly/38DCHTY

30. Milburn K (1995) A critical review of peer education with young people with special reference to sexual health. Health education research 10: 407-420. Link: https://bit.ly/2Kat6dK

31. Bodger JA (2006) Taking the sting out of reporting requirements: reproductive health clinics and the constitutional right to informational privacy. Duke LJ 56 583. Link: https://bit.ly/3co67as

32. Van Wees H (2004) Greek warfare: myths and realities (p. 252). London: Duckworth.

33. Dougherty L (Ed.) (2015) The Royal Marsden manual of clinical nursing procedures. John Wiley \& Sons. Link: https://bit.ly/3ab40WE

34. 34. Corr PJ (2004) Reinforcement sensitivity theory and personality. Neurosc Biobehav Rev .28: 317-332. Link: https://bit.ly/34E7oba

35. Oulton JA (2006) The global nursing shortage: an overview of issues and actions. Policy, Politics, \& Nursing Practice 7: 34S-39S. Link: https://bit.ly/2wHuRM7

\section{Discover a bigger Impact and Visibility of your article publication with} Peertechz Publications

\section{Highlights}

* Signatory publisher of ORCID

* Signatory Publisher of DORA (San Francisco Declaration on Research Assessment)

* Articles archived in worlds' renowned service providers such as Portico, CNKI, AGRIS, TDNet, Base (Bielefeld University Library), CrossRef, Scilit, J-Gate etc.

* Journals indexed in ICMJE, SHERPA/ROMEO, Google Scholar etc.

* OAI-PMH (Open Archives Initiative Protocol for Metadata Harvesting)

* Dedicated Editorial Board for every journa

* Accurate and rapid peer-review process

* Increased citations of published articles through promotions

* Reduced timeline for article publication

Submit your articles and experience a new surge in publication services (https://www.peertechz.com/submission).

Peertechz journals wishes everlasting success in your every endeavours.

Copyright: @ 2020 Kiggindu GK, et al. This is an open-access article distributed under the terms of the Creative Commons Attribution License, which permits unrestricted use, distribution, and reproduction in any medium, provided the original author and source are credited.

Citation: Kiggundu GK, Nyashanu M, Ekpenyong SM (2020) Factors influencing the uptake of family planning services among young people (18-24 years) at community level in rural Budaka district, Uganda. Int J Sex Reprod Health Care 3(1): 005-011. DOI: https://dx.doi.org/10.17352/ijsrhc.000009 